\title{
Synthesis, Properties and Crystal Structure of a Novel Ni(II) Complex Derived from a 4-Heterocyclic Acylpyrazolone
}

\author{
Yong-Jie Ding, Chun-Xiang Zhao, Chao-Yu Pei, and Guo-Xuan Wen \\ Department of Chemistry, Zhoukou Normal University, Zhoukou 466001, P. R. China \\ Reprint requests to Dr. Yongjie Ding. Fax: 86-394-8178253. E-mail: yongjieding@163.com
}

Z. Naturforsch. 2012, 67b, 204 -208; received December 3, 2011

\begin{abstract}
The new 4-acylpyrazolone 1-(4-chlorophenyl)-3-phenyl-4-thenoyl-1H-pyrazol-5-ol (HCPTP) and its $\mathrm{Ni}(\mathrm{II})$ complex $\left[\mathrm{Ni}(\mathrm{CPTP})_{2}\left(\mathrm{C}_{2} \mathrm{H}_{5} \mathrm{OH}\right)_{2}\right]\left(\mathrm{C}_{2} \mathrm{H}_{5} \mathrm{OH}\right)_{2}$ were synthesized. The ligand and the complex were characterized by elemental analyses, IR and UV/Vis spectroscopy, thermal analyses, and single-crystal X-ray diffraction. Crystals of HCPTP are monoclinic, space group $P 2_{1} / c$ with $Z=4$ while $\left[\mathrm{Ni}(\mathrm{CPTP})_{2}\left(\mathrm{C}_{2} \mathrm{H}_{5} \mathrm{OH}\right)_{2}\right]\left(\mathrm{C}_{2} \mathrm{H}_{5} \mathrm{OH}\right)_{2}$ belongs to the triclinic system, space group $P \overline{1}$ with $\mathrm{Z}=$ 2. The complex has a six-coordinated $\mathrm{Ni}(\mathrm{II})$ center in a distorted octahedral configuration with two ethanol ligands in cis position. These octahedral units are connected through hydrogen bonds via the coordinated and uncoordinated ethanol molecules.
\end{abstract}

Key words: Acylpyrazolone, Nickel Complex, Crystal Structure, Spectral Characterization

\section{Introduction}

Acylpyrazolones are an interesting class of $\beta$ diketone compounds which are widely used in the solvent extractions of metal ions, laser working materials and NMR shift reagents [1-3]. Their metal complexes have been found to display catalytic performance, biological activity and enhanced luminescence [4]. In addition, they are potential antifungal agrochemicals, and show antiviral, antipyretic analgesic, and antiinflammatory activity in medicine $[5,6]$.

It is well known that $\mathrm{Ni}(\mathrm{II})$ is a good candidate for the construction of magnetic or luminescent metal-organic materials $[7,8]$, because it can adopt diverse coordination modes with $\mathrm{N}$ - or $O$-donor ligands. HCPTP (1-(4-chlorophenyl)-3-phenyl-4thenoyl-1H-pyrazol-5-ol, 1) is a new 4-heterocyclic acylpyrazolone the formula of which is shown in Scheme 1. In this paper, we present the synthesis of a $\mathrm{CPTP}^{-}$-containing $\mathrm{Ni}(\mathrm{II})$ complex, $\left[\mathrm{Ni}(\mathrm{CPTP})_{2}-\right.$ $\left.\left(\mathrm{C}_{2} \mathrm{H}_{5} \mathrm{OH}\right)_{2}\right]\left(\mathrm{C}_{2} \mathrm{H}_{5} \mathrm{OH}\right)_{2}$ (2), and report its singlecrystal structure, IR- and UV/Vis-spectral properties, and thermal analysis.

\section{Results and Discussion}

HCPTP 1 and the Ni(II) complex $\mathbf{2}$ were synthesized according to established procedures which are summarized in Scheme 1. Further details are given in the Experimental Section.

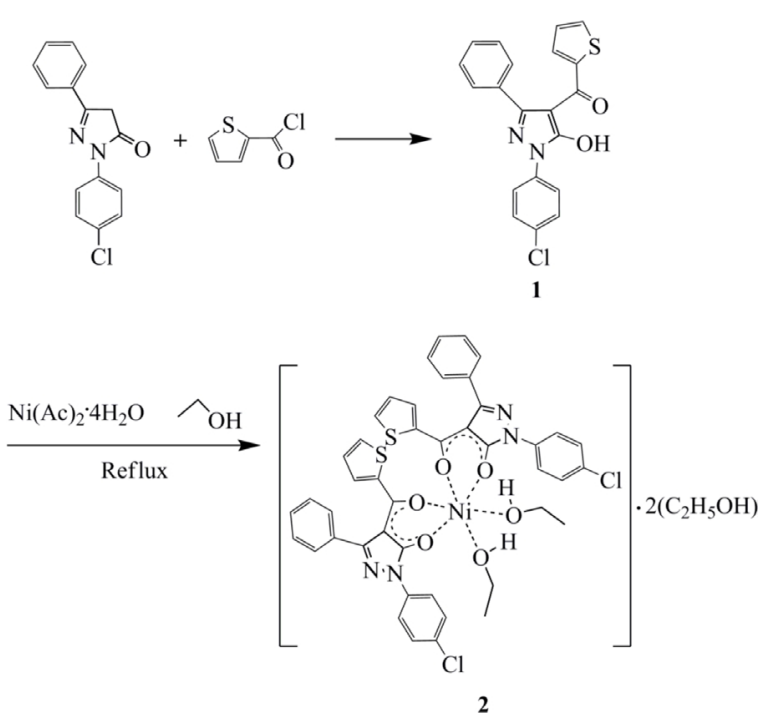

Scheme 1. The synthesis of HCPTP $(\mathbf{1})$ and $\left[\mathrm{Ni}(\mathrm{CPTP})_{2}-\right.$ $\left.\left(\mathrm{C}_{2} \mathrm{H}_{5} \mathrm{OH}\right)_{2}\right]\left(\mathrm{C}_{2} \mathrm{H}_{5} \mathrm{OH}\right)_{2}(2)$.

\section{Description of the molecular structures}

The molecular structure of $\mathbf{1}$ is shown in Fig. 1. Table 1 contains selected distances and angles. The chlorophenyl ring is slightly twisted by $17.79(6)^{\circ}$ with respect to the pyrazolone ring, and the dihedral angles of the phenyl and thenoyl rings with the pyrazolone are $43.10(5)$ and $34.00(8)^{\circ}$, respectively. The clear evidence of the hydroxyl $\mathrm{H}$ atom in the difference 
Table 1. Selected bond lengths $(\AA)$ and angles (deg) for $\mathrm{HCPTP}(\mathbf{1})$ and $\left[\mathrm{Ni}(\mathrm{CPTP})_{2}\left(\mathrm{C}_{2} \mathrm{H}_{5} \mathrm{OH}\right)_{2}\right]\left(\mathrm{C}_{2} \mathrm{H}_{5} \mathrm{OH}\right)_{2}$ (2) with estimated standard deviations in parentheses.

\begin{tabular}{lcll}
\hline & $\mathbf{1}$ & & $\mathbf{2}$ \\
\hline N2-N1 & $1.3890(15)$ & Ni1-O1 & $2.0075(16)$ \\
O2-C16 & $1.2393(17)$ & Ni1-O2 & $2.0281(17)$ \\
C11-C3 & $1.7410(13)$ & Ni1-O3 & $2.0532(17)$ \\
O1-C7 & $1.3214(16)$ & Ni1-O4 & $2.0345(16)$ \\
S1-C20 & $1.6972(18)$ & Ni1-O5 & $2.0725(18)$ \\
S1-C17 & $1.7234(13)$ & Ni1-O6 & $2.0626(19)$ \\
N2-C9 & $1.3222(17)$ & O1-C7 & $1.260(3)$ \\
& & O3-C29 & $1.278(3)$ \\
C9-N2-N1 & $105.57(10)$ & O1-Ni1-O2 & $89.50(7)$ \\
N2-N1-C6 & $118.71(10)$ & O1-Ni1-O3 & $88.92(7)$ \\
O2-C16-C17 & $119.02(12)$ & O1-Ni1-O6 & $90.94(7)$ \\
C20-S1-C17 & $91.80(8)$ & O1-Ni1-O5 & $90.46(7)$ \\
C7-N1-N2 & $110.83(10)$ & O4-Ni1-O2 & $89.82(7)$ \\
C7-N1-C6 & $130.45(11)$ & O4-Ni1-O3 & $88.21(7)$ \\
O2-C16-C8 & $117.86(12)$ & O4-Ni1-O5 & $90.25(7)$ \\
& & O4-Ni1-O6 & $91.95(7)$ \\
\hline
\end{tabular}

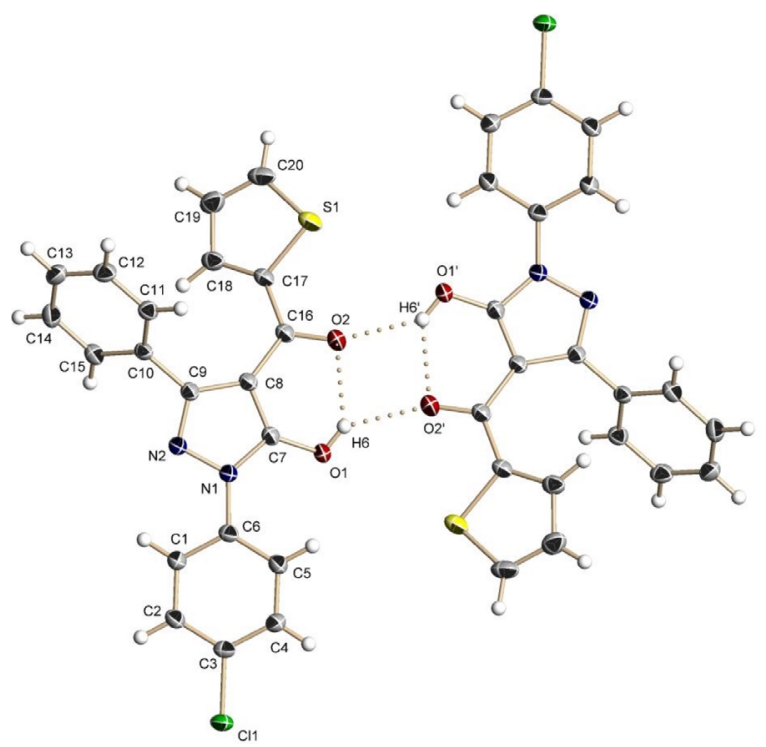

Fig. 1 (color online). The structure of a dimer of HCPTP (1) in the solid state with atom numbering scheme adopted. (Hydrogen bonds are shown as dotted lines. Displacement ellipsoids are drawn at the $30 \%$ probability level. $\mathrm{H}$ atoms are represented as small spheres of arbitrary radius. Symmetry code: $\left.\left({ }^{\prime}\right)-x, 1-y, 2-z\right)$.

Fourier synthesis and the absence of any residual electron density in the vicinity of $\mathrm{C} 8$ confirm that 1 crystallizes as a pure enol tautomer and that no desmotropism is present [9]. Atom $\mathrm{O} 2$ has a partial anionic character, as shown by the lengthening of the $\mathrm{C}=\mathrm{O}$ bond [1.2393(17) $\AA$ ] relative to that normally found for carbonyl groups, and this atom acts as hydrogen-bond acceptor (Table 1 and Fig. 1). The intermolecular hydro- gen bond results in the formation of a dimer with an $\mathrm{R}_{2}^{2}$ (12) graph-set motif [10].

The structure of $\left[\mathrm{Ni}(\mathrm{CPTP})_{2}\left(\mathrm{C}_{2} \mathrm{H}_{5} \mathrm{OH}\right)_{2}\right]\left(\mathrm{C}_{2}\right.$ $\left.\mathrm{H}_{5} \mathrm{OH}\right)_{2}$ (2) together with the atom numbering scheme is illustrated in Fig. 2. Important distances and angles are summarized in Table 1. The structure determination revealed a 6-coordinate mononuclear $\mathrm{Ni}$ (II) complex with the metal coordinated by two oxygen atoms of ethanol and four oxygen atoms of two bidentate pyrazolonate ligands $\mathrm{CPTP}^{-}$.

The coordination around the Ni center is a slightly distorted octahedron (Fig. 2). The two Ni-coordinated ethanol molecules are mutually cis, while the two bidentate $\mathrm{CPTP}^{-}$ligands adopt the deprotonated enol form, chelating to the $\mathrm{Ni}$ atom via their $\mathrm{O}$ atoms. The cis-configuration may be facilitated by intermolecular hydrogen bonds between the coordinated and uncoordinated ethanol molecules (see below).

The structure of the neutral ligand $\mathbf{1}$ has changed in the $\mathrm{Ni}(\mathrm{II})$ complex 2. The $\mathrm{O}(1)-\mathrm{C}(7)$ and $\mathrm{O}(3)-\mathrm{C}(29)$ bond lengths are 1.260(3) and 1.278(3) $\AA$, respectively, which is shorter than $1.3214(16) \AA$ for the $\mathrm{O}(1)-\mathrm{C}(7)$ single bond of the free ligand and longer than $1.22 \AA$

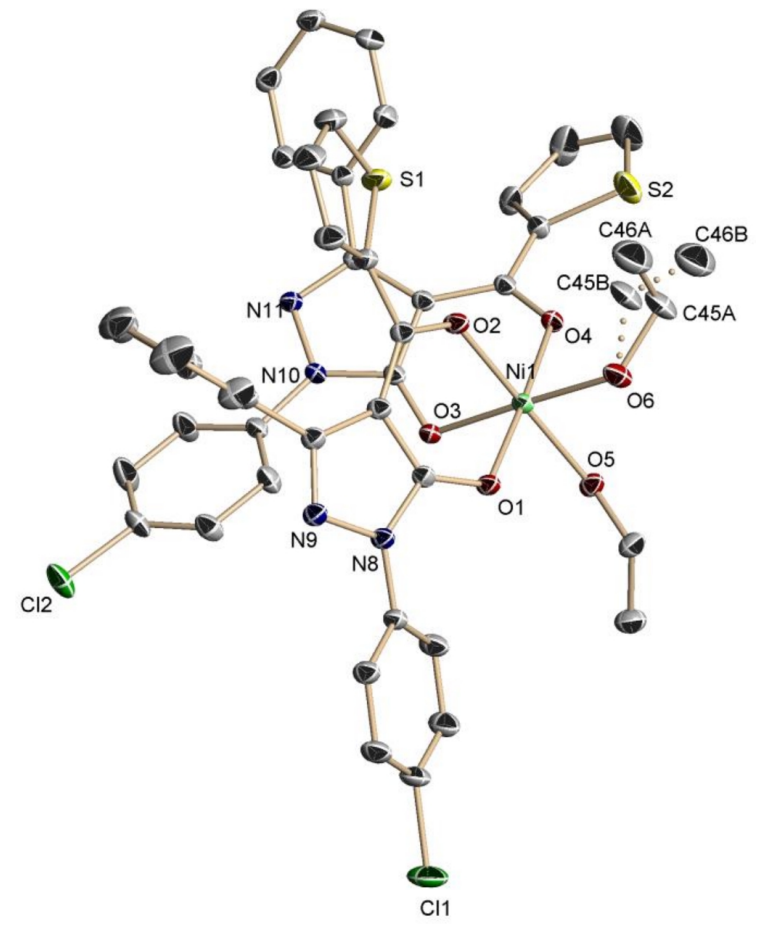

Fig. 2 (color online). The molecular structure of $\left[\mathrm{Ni}(\mathrm{CPTP})_{2}-\right.$ $\left.\left(\mathrm{C}_{2} \mathrm{H}_{5} \mathrm{OH}\right)_{2}\right]\left(\mathrm{C}_{2} \mathrm{H}_{5} \mathrm{OH}\right)_{2}(2)$ in the solid state. (30\% probability ellipsoids. The two uncoordinated ethanol molecule are omitted for clarity). 
Table 2. Hydrogen bonds for complex $2(\AA \text { and deg })^{\mathrm{a}}$.

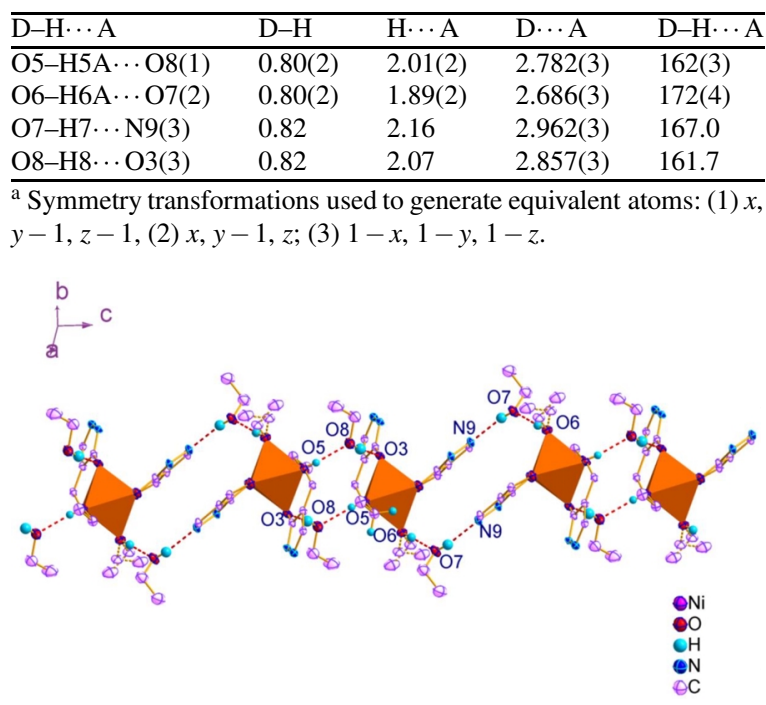

Fig. 3 (color online). View of the crystal structure of $\left[\mathrm{Ni}(\mathrm{CPTP})_{2}\left(\mathrm{C}_{2} \mathrm{H}_{5} \mathrm{OH}\right)_{2}\right]\left(\mathrm{C}_{2} \mathrm{H}_{5} \mathrm{OH}\right)_{2}$ (2). Some atoms were omitted for clarity.

for a $\mathrm{C}=\mathrm{O}$ double bond. Moreover, the $\mathrm{C}(7)-\mathrm{C}(8)$ and $\mathrm{C}(28)-\mathrm{C}(29)$ bond lengths are close to that of $\mathrm{C}-\mathrm{C}$ single bonds, confirming that the enol form of the ligand has isomerized to the keto form. These changes indicate a delocalized pyrazolone-ring, averaging the bond lengths.

The crystal strcuture of $\left[\mathrm{Ni}(\mathrm{CPTP})_{2}\left(\mathrm{C}_{2} \mathrm{H}_{5} \mathrm{OH}\right)_{2}\right]-$ $\left(\mathrm{C}_{2} \mathrm{H}_{5} \mathrm{OH}\right)_{2}$ (2) contains two co-crystallized uncoordinated alcohol molecules, which are linked via hydrogen bonding to the coordinated ethanol molecules (atoms $\mathrm{O} 8$ and O7; see Table 2 and Fig. 3). The latter, in turn, act as hydrogen bond donors to atoms N9 and $\mathrm{O} 3$ of neighboring complexes. Thus, the molecules form double-chains of hydrogen bonds along the $c$ axis, and a one-dimensional supramolecular structure is formed.

\section{IR and UV/Vis spectra}

The infrared spectrum of $\mathbf{1}$ was compared with that of the complex 2 (Fig. 4). In 1, a medium-intensity band at $3072 \mathrm{~cm}^{-1}$ is assigned to $v(\mathrm{OH})$ of the $\beta$ diketone. The band is absent in the complex. A band at $1591 \mathrm{~cm}^{-1}$ in the free ligand allocated as $v(\mathrm{C}=\mathrm{O})$ of the pyrazolone ring is shifted to $1572 \mathrm{~cm}^{-1}$ in the complex [11]. The weak band at $467 \mathrm{~cm}^{-1}$ is related to a Ni-O stretching vibration. From these observations it is concluded that the enolic proton of the ligand is absent in the $\mathrm{Ni}$ (II) complex.

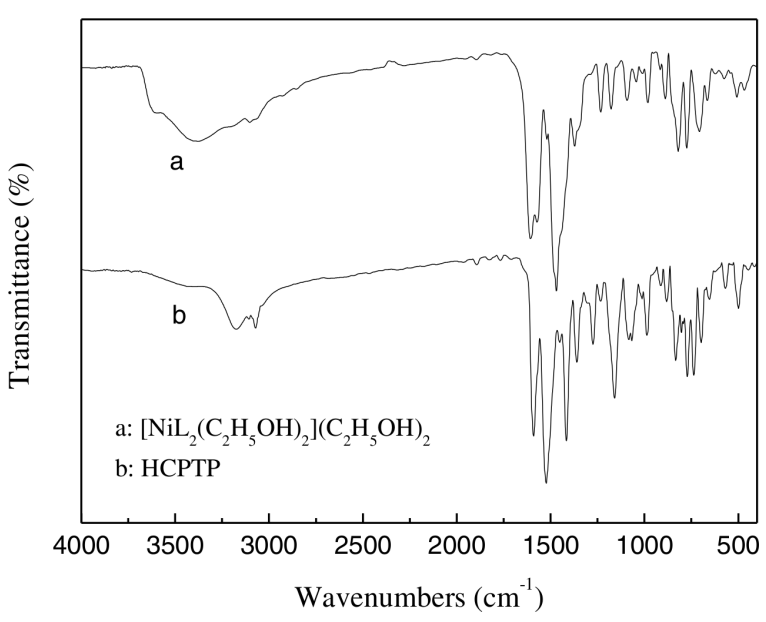

Fig. 4. FT-IR spectra of $\mathbf{1}$ and $\mathbf{2}$.

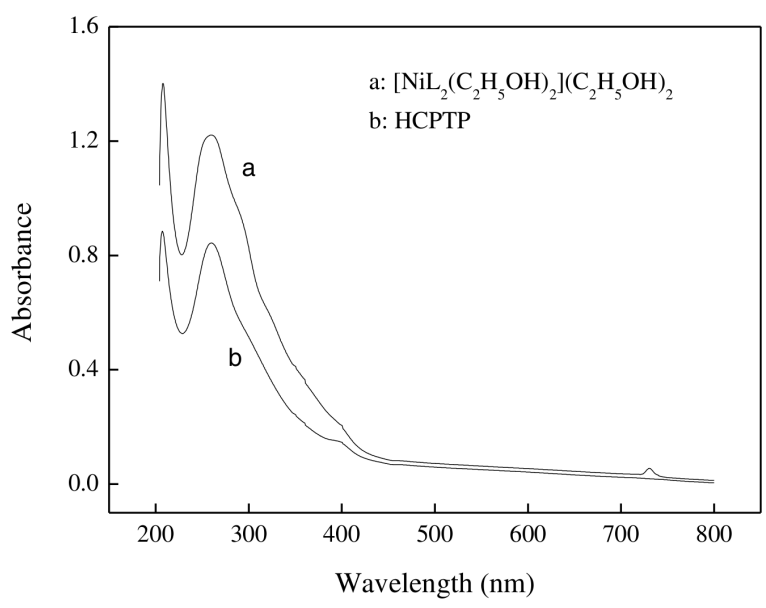

Fig. 5. UV/Vis spectra of $\mathbf{1}$ and 2.

UV/Vis absorption spectra (Fig. 5) of $\mathbf{1}$ and the complex 2 in ethanolic solutions were recorded in the range from 200 to $800 \mathrm{~nm}$. The two absorptions of the complex at 208 and $260 \mathrm{~nm}$ are assigned to $\pi-\pi^{*}$ transitions of the aryl ring and carbonyl group [12]. Compared with the electronic spectral data of the free ligand, the absorption peaks do not show an obvious shift. In the visible region, very weak absorptions near $730 \mathrm{~nm}$ for the $\mathrm{Ni}$ (II) complex are assigned to $d$ - $d$ transitions [13], consistent with nickel in an octahedral environment.

\section{Thermal analysis}

The thermal stability of a crystal is an important factor for crystal growth and potential applications. Therefore, DSC and TG analyses were carried out over 

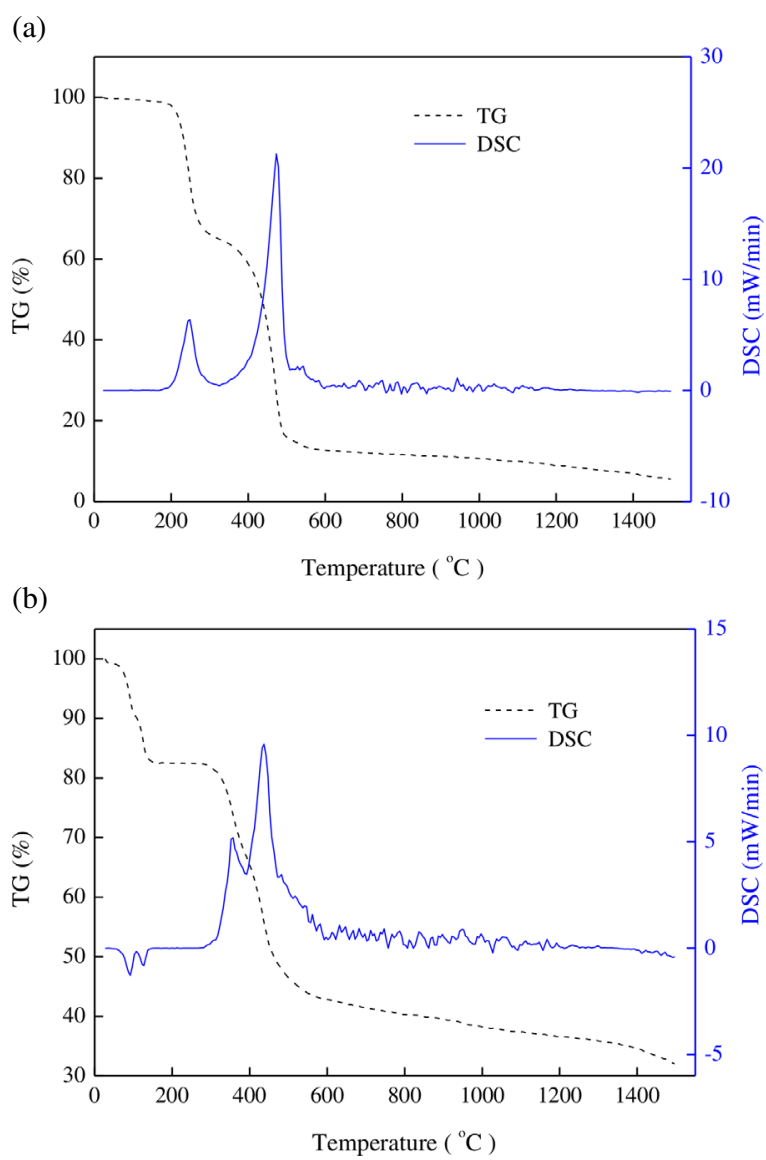

Fig. 6 (color online). TG-DSC curves of $\mathbf{1}$ (a) and $\mathbf{2}$ (b).

the temperature range from 25 to $1500{ }^{\circ} \mathrm{C}$ under a nitrogen atmosphere.

The TG-DSC curves of $\mathbf{1}$ and $\mathbf{2}$ are shown in Fig. 6. The HCPTP molecule (1) began to decompose at $168{ }^{\circ} \mathrm{C}$. The TG-DSC curves of $\left[\mathrm{Ni}(\mathrm{CPTP})_{2}-\right.$ $\left.\left(\mathrm{C}_{2} \mathrm{H}_{5} \mathrm{OH}\right)_{2}\right]\left(\mathrm{C}_{2} \mathrm{H}_{5} \mathrm{OH}\right)_{2}$ (2) shows decomposition of the complex in three steps. The first step at about $52-$ $102{ }^{\circ} \mathrm{C}$ with a mass loss of $9.1 \%$ (calcd. $9.2 \%$ ) is due to the evolution of two solvate ethanol molecules, for which the DSC curve shows an endothermic peak. The second decomposition at $102-167{ }^{\circ} \mathrm{C}$ with a mass loss of $8.6 \%$ is close to the theoretical mass loss of two ethanol molecules coordinated to $\mathrm{Ni}$. The last step occurs at $267-592{ }^{\circ} \mathrm{C}$, accompanied by two exothermic peaks in the DSC curve due to the decomposition of the organic residues.

In summary, a new 4-heterocyclic acylpyrazolone nickel(II) complex $\left[\mathrm{Ni}(\mathrm{CPTP})_{2}\left(\mathrm{C}_{2} \mathrm{H}_{5} \mathrm{OH}\right)_{2}\right]-$ $\left(\mathrm{C}_{2} \mathrm{H}_{5} \mathrm{OH}\right)_{2}$ has been synthesized. The coordination around the $\mathrm{Ni}$ is a slightly distorted octahedron. In-
Table 3. Crystallographic data for $\mathrm{HCPTP}(\mathbf{1})$ and $\left[\mathrm{NiL}_{2}\left(\mathrm{C}_{2}-\right.\right.$ $\left.\left.\mathrm{H}_{5} \mathrm{OH}\right)_{2}\right]\left(\mathrm{C}_{2} \mathrm{H}_{5} \mathrm{OH}\right)_{2}(2)$.

\begin{tabular}{|c|c|c|}
\hline & $\mathbf{1}$ & 2 \\
\hline$\overline{\text { Formula }}$ & $\mathrm{C}_{20} \mathrm{H}_{13} \mathrm{ClN}_{2} \mathrm{O}_{2} \mathrm{~S}$ & $\mathrm{C}_{48} \mathrm{H}_{48} \mathrm{C}_{l 2} \mathrm{~N}_{4} \mathrm{NiO}_{8} \mathrm{~S}_{2}$ \\
\hline$M_{\mathrm{r}}$ & 380.84 & 1002.63 \\
\hline Crystal size, $\mathrm{mm}^{3}$ & $0.25 \times 0.20 \times 0.20$ & $0.37 \times 0.30 \times 0.30$ \\
\hline Crystal system & monoclinic & triclinic \\
\hline Space group & $P 2_{1} / c$ & $P \overline{1}$ \\
\hline$a, \AA$ & $6.0686(2)$ & $11.8800(6)$ \\
\hline$b, \AA$ & $18.6887(5)$ & $14.1744(7)$ \\
\hline$c, \AA$ & $14.9734(4)$ & $14.5643(7)$ \\
\hline$\alpha, \operatorname{deg}$ & 90 & $91.598(1)$ \\
\hline$\beta, \operatorname{deg}$ & $91.559(1)$ & $104.050(1)$ \\
\hline$\gamma, \operatorname{deg}$ & 90 & $91.335(1)$ \\
\hline$V, \AA^{3}$ & $1697.57(9)$ & 2377.1(2) \\
\hline$Z$ & 4 & 2 \\
\hline$D_{\text {calcd }}, \mathrm{g} \mathrm{cm}^{-3}$ & 1.49 & 1.40 \\
\hline$\mu\left(\operatorname{Mo} K_{\alpha}\right), \mathrm{cm}^{-1}$ & 0.4 & 0.7 \\
\hline$F(000), \mathrm{e}$ & 784.0 & 1044 \\
\hline$h k l$ range & $\begin{array}{l}-7 \rightarrow+8, \pm 24 \\
\pm 19\end{array}$ & $\begin{array}{l}-14+13, \pm 17 \\
-16 \rightarrow+17\end{array}$ \\
\hline$((\sin \theta) / \lambda)_{\max }, \AA^{-1}$ & 0.667 & 0.606 \\
\hline Refl. measured / & 22656 & 28134 \\
\hline unique / & 4206 & 8847 \\
\hline$R_{\text {int }}$ & 0.0239 & 0.0250 \\
\hline Param. refined & 236 & 606 \\
\hline$R(F) / w R\left(F^{2}\right)^{\mathrm{a}}$ (all refl.) & $0.0337 / 0.0913$ & $0.0390 / 0.1036$ \\
\hline $\mathrm{GoF}\left(F^{2}\right)^{\mathrm{b}}$ & 1.061 & 1.042 \\
\hline$\Delta \rho_{\text {fin }}(\max / \min ), \mathrm{e}^{-3}$ & $0.36 /-0.30$ & $0.90 /-0.37$ \\
\hline \multicolumn{3}{|c|}{$\begin{array}{l}{ }^{\mathrm{a}} R 1=\left\|F_{\mathrm{o}}|-| F_{\mathrm{c}}\right\| / \Sigma\left|F_{\mathrm{o}}\right|, w R 2=\left[\Sigma w\left({F_{\mathrm{o}}}^{2}-{F_{\mathrm{c}}}^{2}\right)^{2} / \Sigma w\left(F_{\mathrm{o}}{ }^{2}\right)^{2}\right]^{1 / 2} \\
w=\left[\sigma^{2}\left(F_{\mathrm{o}}{ }^{2}\right)+(\mathrm{A} P)^{2}+\mathrm{B} P\right]^{-1} \text {, where } P=\left(\operatorname{Max}\left(F_{\mathrm{o}}{ }^{2}, 0\right)+2 F_{\mathrm{c}}{ }^{2}\right) / 3 \\
\text { and } \mathrm{A} \text { and } \mathrm{B} \text { are constants adjusted by the program; }{ }^{\mathrm{b}} \mathrm{GoF}= \\
{\left[\sum w\left(F_{\mathrm{o}}{ }^{2}-F_{\mathrm{c}}{ }^{2}\right)^{2} /\left(n_{\mathrm{obs}}-n_{\mathrm{param}}\right)\right]^{1 / 2} \text {, where } n_{\mathrm{obs}} \text { is the number of }} \\
\text { data and } n_{\text {param }} \text { the number of refined parameters. }\end{array}$} \\
\hline
\end{tabular}

termolecular hydrogen bonds $\mathrm{O}-\mathrm{H} \cdots \mathrm{O}$ and $\mathrm{O}-\mathrm{H} \cdots \mathrm{N}$ provide further stability.

\section{Experimental Section}

\section{General methods and materials}

All reagents were obtained from commercial sources and used without purification. $\mathrm{C}, \mathrm{H}$ and $\mathrm{N}$ analyses were carried out with an Elementar vario EL III elemental analyzer. Infrared spectra were recorded using a Nicolet 5700 spectrophotometer $\left(4000-400 \mathrm{~cm}^{-1}\right)$ with a crystalline sample in $\mathrm{KBr}$ pellets. Thermal analysis was performed on a Netzsch STA449F3 TG-DSC thermal analyzer in an atmosphere of $\mathrm{N}_{2}$ with a heating rate of $5 \mathrm{~K} \mathrm{~min}^{-1}$. UV/Vis spectra were recorded on a Perkin-Elmer Lambda35 spectrophotometer.

\section{Synthesis of HCPTP (1, Scheme 1)}

Compound 1 was synthesized from 1-(4-chlorophenyl)-3-phenyl-1H-pyrazol-5(4H)-one and 2-thenoyl chloride (thiophene-2-carbonyl chloride) and purified according to the method proposed by Jensen [14]. Starting materials: 1-(4-chlorophenyl)-3-phenyl-1H-pyrazol-5(4H)-one, $6.77 \mathrm{~g}$, 
$25 \mathrm{mmol}$; 2-thenoyl chloride, $2.68 \mathrm{~mL}, 25 \mathrm{mmol}$. The overall yield was $73 \%$. - Analysis for $\mathrm{C}_{20} \mathrm{H}_{13} \mathrm{ClN}_{2} \mathrm{O}_{2} \mathrm{~S}$ : calcd. C 63.07, H 3.18, N 7.36; found C 63.02, H 3.12, N 7.41. Block-shaped golden single crystals suitable for singlecrystal X-ray diffraction were grown from toluene by slow evaporation of the solvent over a period of several days.

\section{Synthesis of $\left[\mathrm{Ni}(\mathrm{CPTP})_{2}\left(\mathrm{C}_{2} \mathrm{H}_{5} \mathrm{OH}\right)_{2}\right]\left(\mathrm{C}_{2} \mathrm{H}_{5} \mathrm{OH}\right)_{2}$ (2; Scheme 1)}

A mixture of a $10 \mathrm{~mL}$ of a solution of HCPTP $(2 \mathrm{mmol}$, $0.5365 \mathrm{~g}$ ) in anhydrous ethanol and $10 \mathrm{~mL}$ of an ethanolic solution of $\mathrm{Ni}(\mathrm{Ac})_{2} \cdot 4 \mathrm{H}_{2} \mathrm{O}(1 \mathrm{mmol}, 0.2488 \mathrm{~g})$ was refluxed for $4 \mathrm{~h}$ at $75-80{ }^{\circ} \mathrm{C}$. Green single crystals were obtained by slow evaporation of the solvent from the reaction mixture at r.t. after several days; yield: $87 \%$. - Analysis for $\mathrm{C}_{34} \mathrm{H}_{34} \mathrm{~N}_{4} \mathrm{O}_{8} \mathrm{Ni}(\%)$ : calcd. C 59.59, H 5.00, N 8.18; found C 59.75, H 4.92, N 8.05.

\section{Crystal structure determinations}

Crystallographic measurements were made on a Bruker Smart CCD single-crystal diffractometer with $\mathrm{Mo} K_{\alpha}$ radiation $(\lambda=0.71073 \AA$ ) by using $\phi$ and $\omega$ scan techniques at r.t. Accurate unit cell parameters and the orientation ma- trix were obtained from least-squares refinements using the programs SMART and SAINT [15], and the data were integrated using SAINT. The structures were solved by Direct Methods (SHELXS-97 [16]) and refined by full-matrix leastsquares techniques on $F^{2}$ using SHELXL-97 [16]. The hydrogen atoms were observed in the difference Fourier syntheses or placed geometrically and treated as riding on their parent atoms except $\mathrm{H}$ atoms of $\mathrm{OH}$. The $\mathrm{C}$ atoms $(\mathrm{C} 45 \mathrm{~A}, \mathrm{C} 45 \mathrm{~B}$ and $\mathrm{C} 46 \mathrm{~A}, \mathrm{C} 46 \mathrm{~B}$ ) of one of the two ethanol molecules coordinated to the $\mathrm{Ni}$ atom were found to be disordered over two sites in a ratio of $0.593(5): 0.407(5)$. Table 3 contains the crystal data and numbers pertinent to the data collection and structure refinement of $\mathbf{1}$ and $\mathbf{2}$.

CCDC 846953 and 846813 contain the supplementary crystallographic data for this paper. These data can be obtained free of charge from The Cambridge Crystallographic Data Centre via www.ccdc.cam.ac.uk/data_request/cif.

\section{Acknowledgement}

The authors gratefully acknowledge financial support by the Scientific Research Innovation Foundation for youth teachers of Zhoukou Normal University (No. zknuqn201044B).
[1] S. Yamazaki, M. Hanada, Y. Yanase, C. Fukumori, K. Ogura, T. Saeki, S. Umetani, J. Chem. Soc., Perkin Trans. 1999, 693-696.

[2] C. Pettinari, F. Marchetti, A. Drozdov in Comprehensive Coordination Chemistry II, Vol. 1, (Eds.: J. A. McCleverty, T. J. Meyer), Elsevier, Amsterdam, 2003, pp. $97-115$.

[3] G.X. Zheng, Q.F. Wang, S. G. Luo, J. Radioanal. Nucl. Chem. 2003, 258, 693-696

[4] F. Marchetti, C. Pettinari, R. Pettinari, Coord. Chem. Rev. 2005, 249, 2909-2945.

[5] J.Z. Li, W. J. Yu, X. Y. Du, Chin. J. Appl. Chem. 1997, $14,98-100$.

[6] J. M. Liu, R. D. Yang, T. R. Ma, Chem. J. Chin. Univ. 1980, 1, 23-29.

[7] J. Li, J. Z Li, H. Q. Zhang, Y. Zhang, J. Q. Li, J. Coord. Chem. 2009, 62, $2465-2471$.

[8] F. C. Liu, Y. F. Zeng, J. Jiao, X. H. Bu, J. Ribas, S. R. Batten, Inorg. Chem. 2006, 45, 2776-2778.
[9] C. Foces-Foces, C. Fontenas, J. Elguero, I. Sobrados, An. Quim. Int. Ed. 1997, 93, 219-224.

[10] M. C. Etter, J. C. MacDonald, J. Bernstein, Acta Crystallogr. 1990, B46, 256-262.

[11] E.C. Okafo, Spectrochim. Acta 1981, A37, 945950.

[12] A. B. P. Lever, Inorganic Electronic Spectroscopy, Elsevier, Amsterdam, 1984, p. 161.

[13] B. N. Figgis, J. Lewis, Progress in Inorganic Chemistry, Interscience, New York, Vol. 6, 1964, p. 192.

[14] B. S. Jensen, Acta Chem. Scand. 1959, 13, 1668 - 1670.

[15] Smart, SAINT, Bruker Analytical X-ray Instruments Inc., Madison, Wisconsin (USA) 1998.

[16] G. M. Sheldrick, SHELXS/L-97, Programs for Crystal Structure Determination, University of Göttingen, Göttingen (Germany) 1997. See also: G. M. Sheldrick, Acta Crystallogr. 1990, A46, 467-473; ibid. 2008, A64, 112 - 122. 